Nascimento, Dandara Lorrayne do et al. Minicurso: construções de triângulos através do software Geogebra

\title{
MINICURSO: CONSTRUÇÕES DE TRIÂNGULOS ATRAVÉS DO SOFTWARE GEOGEBRA $^{1}$
}

\author{
Dandara Lorrayne do Nascimento ${ }^{2}$ \\ Daiana Luiza de $\mathrm{Sá}^{3}$ \\ Thayná Pereira Vieira ${ }^{4}$ \\ Lúcia Helena Costa Braz ${ }^{5}$
}

\begin{abstract}
RESUMO
Este trabalho apresenta uma experiência metodológica vivenciada com os alunos do $1^{\circ}$ ano Técnico Integrado do Instituto Federal de Educação, Ciência e Tecnologia de Minas Gerais Campus Formiga. Foi ministrado um minicurso com o objetivo de introduzir o uso do software Geogebra possibilitando um novo pensar matemático através de recursos tecnológicos, mediante aplicação pedagógica na execução de algumas construções geométricas no Laboratório de Informática. Optou-se por trabalhar atividades de natureza exploratório-investigativa, onde os alunos tiveram a oportunidade de testar os conhecimentos teóricos na prática através das manipulações, observações e discussões. Como já esperado, nem todos os alunos possuíam os conhecimentos prévios que deveriam ser vistos no Ensino Fundamental, caracterizando a principal hipótese de que o ensino da geometria ainda se encontra degradado, porém com o uso de recursos tecnológicos as atividades se mostraram satisfatórias alcançando o principal objetivo no ensino da geometria plana.
\end{abstract}

Palavras-chave: Geometria Plana. Construções de triângulos. Geogebra.

\section{INTRODUÇÃO}

Na década de 60, com a chegada do Movimento da Matemática Moderna no Brasil, o currículo do ensino da matemática foi modificado com o objetivo de valorizar os conteúdos de estruturas algébricas, aplicando as linguagens simbólicas das teorias dos conjuntos, buscando adaptar os temas de geometria em um aspecto abstrato. Esta prática não era dominada pela maioria dos professores, fazendo com que estes deixassem de abordá-la no

\footnotetext{
${ }^{1}$ Como citar este artigo:

NASCIMENTO, Dandara Lorrayne do et al. Minicurso: construções de triângulos através do software Geogebra. ForScience: revista científica do IFMG, Formiga, v. 5, n. 3, e00308, jul./dez. 2017.

${ }^{2}$ Graduanda em Licenciatura em Matemática - IFMG, campus Formiga. E-mail: dandaralno@gmail.com. Currículo Lattes: http://lattes.cnpq.br/5252418461818762.

${ }^{3}$ Graduanda em Licenciatura em Matemática - IFMG, campus Formiga. E-mail: daianasa12@outlook.com. Currículo Lattes: http://lattes.cnpq.br/0843503780448606.

${ }^{4}$ Graduanda em Licenciatura em Matemática - IFMG, Campus Formiga. E-mail: thaynavieira2012@gmail.com. Currículo Lattes: http://lattes.cnpq.br/4242060131359448.

${ }^{5}$ Mestra profissional em Matemática (Mestrado profissional em Matemática em rede nacional) (2013) pela Universidade Federal de Lavras (UFLA). E-mail: lucia.helena@ifmg.edu.br. Currículo Lattes: http://lattes.cnpq.br/8127215627397170.
} 
ensino de geometria, dando destaque então para os conceitos de álgebra (SOUSA, 1999). Com as mudanças da grade curricular, geradas para estimular o ensino da matemática de acordo com as habilidades e competências que os professores julgassem necessárias, estipulada pela Lei de Diretrizes e Bases (LDB) do $1^{\circ}$ e $2^{\circ}$ graus (lei 5692/71), a maioria dos alunos ficou sem ter conhecimento da geometria que deveria ser estudada, com isso, os professores passaram a dar maior importância para o ensino de aritmética e teoria dos conjuntos, criando desde então uma crise que se estende até os dias atuais no processo de ensino e aprendizagem da geometria plana (PAVANELLO, 1993).

Nos dias atuais, o ensino de Geometria ainda sofre com as interferências do Movimento da Matemática Moderna. Um estudo feito por Barbosa (2003), verifica que os conteúdos de Geometria Plana são sempre trabalhados no último bimestre ou então deixados de lado. Este fato deve-se à grande quantidade de conteúdos matemáticos a serem cumpridos e também à insegurança que alguns docentes sentem em relação ao ensino da geometria.

De acordo com os Parâmetros Curriculares Nacionais (PCN) de Matemática, a geometria plana tem o objetivo de propiciar ao aluno uma noção de espaço, bem como, o reconhecimento de semelhanças e simetrias em diferentes formas da natureza e nas criações artísticas, sendo assim importante para a visualização e contextualização dos conceitos formulados em sala de aula (BRASIL, 1997).

Uma das formas de abordar os conceitos geométricos é através da utilização softwares de visualização gráfica. Neste aspecto, o software Geogebra que tem entre seus objetivos o de dinamizar o estudo da geometria e da álgebra, pode "ser utilizado como um recurso pedagógico em diferentes níveis e modalidades de ensino em matemática como os conteúdos da Geometria Plana”. (PELLI, 2014, p. 215).

Oliveira (2017, p.5) relata que "pesquisas apontam para o uso das Tecnologias da Informação e Comunicação como um meio simplificado para a construção da abstração matemática, a formulação do pensamento crítico e a conceituação por parte dos alunos". Neste aspecto, o principal objetivo desta pesquisa foi proporcionar uma visualização gráfica, através da construção de triângulos, no software Geogebra e assim reforçar e verificar se alguns conceitos geométricos essenciais foram fundamentados ao longo dos anos de estudo pelos alunos ingressantes no $1^{\circ}$ ano Técnico Integrado do Instituto Federal de Educação, Ciência e Tecnologia de Minas Gerais - Campus Formiga. 


\title{
2 DESENVOLVIMENTO
}

\subsection{O uso do Geogebra no ensino da geometria}

Segundo os PCN, o uso do computador e dos softwares matemáticos se torna cada vez mais indispensáveis no processo de ensino e aprendizagem, possibilitando o desenvolvimento cognitivo e de habilidades dos alunos (BRASIL,1997). Nesta linha de pensamento Borba e Penteado (2010) afirmam que

\begin{abstract}
No momento em que os computadores, enquanto artefato cultural e enquanto técnica, ficam cada vez mais presentes em todos os domínios da atividade humana, é fundamental que eles também estejam presentes nas atividades escolares. Na escola, a alfabetização informática precisa ser considerada como algo tão importante quanto a alfabetização na língua materna e em matemática (BORBA; PENTEADO, 2010, p. 87).
\end{abstract}

Neste aspecto, segundo Lovis e Franco (2013), a utilização do Geogebra proporciona fazer diversas construções geométricas, possibilitando a visualização e verificação das propriedades, sendo eficaz para a formulação de conceitos por parte dos alunos.

As atividades geométricas são importantes para o desenvolvimento da noção de forma e espaço que o indivíduo possui, assim, vale ressaltar que:

\footnotetext{
Entende-se que as atividades geométricas podem estimular reflexões e questionamentos matemáticos, todo o caminhar e trabalho exploratório conduzido durante uma atividade geométrica está permeado por situações que contribuem para a constituição de um trabalho investigativo também em atividades matemáticas. (PEREIRA, p. 27, 2012).
}

Pereira (2012) ainda afirma que a interface do software Geogebra (ferramentas geométricas, janela de álgebra e algébrica, campo de entrada de texto, janela para construções tridimensionais, entre outros) incentiva um ambiente de investigação, favorecendo a aprendizagem do aluno.

Ainda sobre o uso do Geogebra, Borba, Silva e Gadanidis (2016, p. 23) acreditam que softwares de geometria dinâmica, como o Geogebra, possibilitam ao aluno "manipular, combinar, visualizar e construir virtualmente objetos geométricos, permitindo traçar novos caminhos de investigação". 
E, neste sentido, Ponte, Brocardo e Oliveira (2009, p. 71) apontam que “A Geometria é particularmente propícia, desde os primeiros anos de escolaridade, a um ensino fortemente baseado na exploração de situações de natureza exploratória e investigativa".

Acredita-se que associar o ensino da Geometria com softwares educacionais, no caso, o Geogebra, e atividades de natureza exploratório-investigativa, onde os alunos têm a oportunidade de testar os conhecimentos teóricos na prática através das manipulações, observações e discussões, pode ser uma maneira mais efetiva de proporcionar a compreensão dos conceitos estudados, além de despertar o interesse dos alunos pelas aulas, o que, naturalmente, tende a favorecer a aprendizagem.

\subsection{Metodologia}

Como meio de elaborar os princípios teóricos e fundamentar a pesquisa, esta foi caracterizada como qualitativa, de caráter exploratório e descritivo.

Com o objetivo de identificar e conceituar a aprendizagem dos alunos foi aplicado um minicurso intitulado "Construções de triângulos através do software Geogebra ${ }^{6}$ para 86 alunos, divididos em três turmas, ingressantes no $1^{\circ}$ ano Técnico Integrado do Instituto Federal de Educação, Ciência e Tecnologia de Minas Gerais - Campus Formiga. O minicurso foi ministrado em três dias consecutivos, sendo um dia para cada turma, com duração total de quatro horas. As atividades foram feitas individualmente, porém foi permitida a interação e discussões entre os alunos.

Inicialmente, foram relembrados alguns conceitos de geometria plana que seriam necessários para o desenvolvimento da atividade, como circunferências, área e perímetro de figuras planas, ângulos formados por retas, conceitos de triângulos semelhantes e congruentes. Posteriormente houve uma explicação quanto à manipulação das ferramentas do software Geogebra. Após todo aporte teórico, as atividades foram iniciadas.

Foram solicitadas as seguintes construções:

I. Crie um triângulo no software Geogebra que tenha os lados medindo $6 \mathrm{~cm}, 5 \mathrm{~cm}$ e 2 $\mathrm{cm}$. Mostre a medida de seus ângulos.

II. Crie um triângulo no software Geogebra que tenha os lados medindo $10 \mathrm{~cm}, 4 \mathrm{~cm}$ e 8 $\mathrm{cm}$.

III. Crie um triângulo isósceles. Mostre a medida de seus ângulos.

\footnotetext{
${ }^{6}$ Versão 5.0.380.0-3D_Java 1.7.0._40- 32 bit, 247 MB, inicializando CAS
}

ForSci.: r. cient. IFMG, Formiga, v. 5, n. 3, e308, jul./dez. 2017. 
IV. Crie um triângulo equilátero. Mostre a medida de seus ângulos.

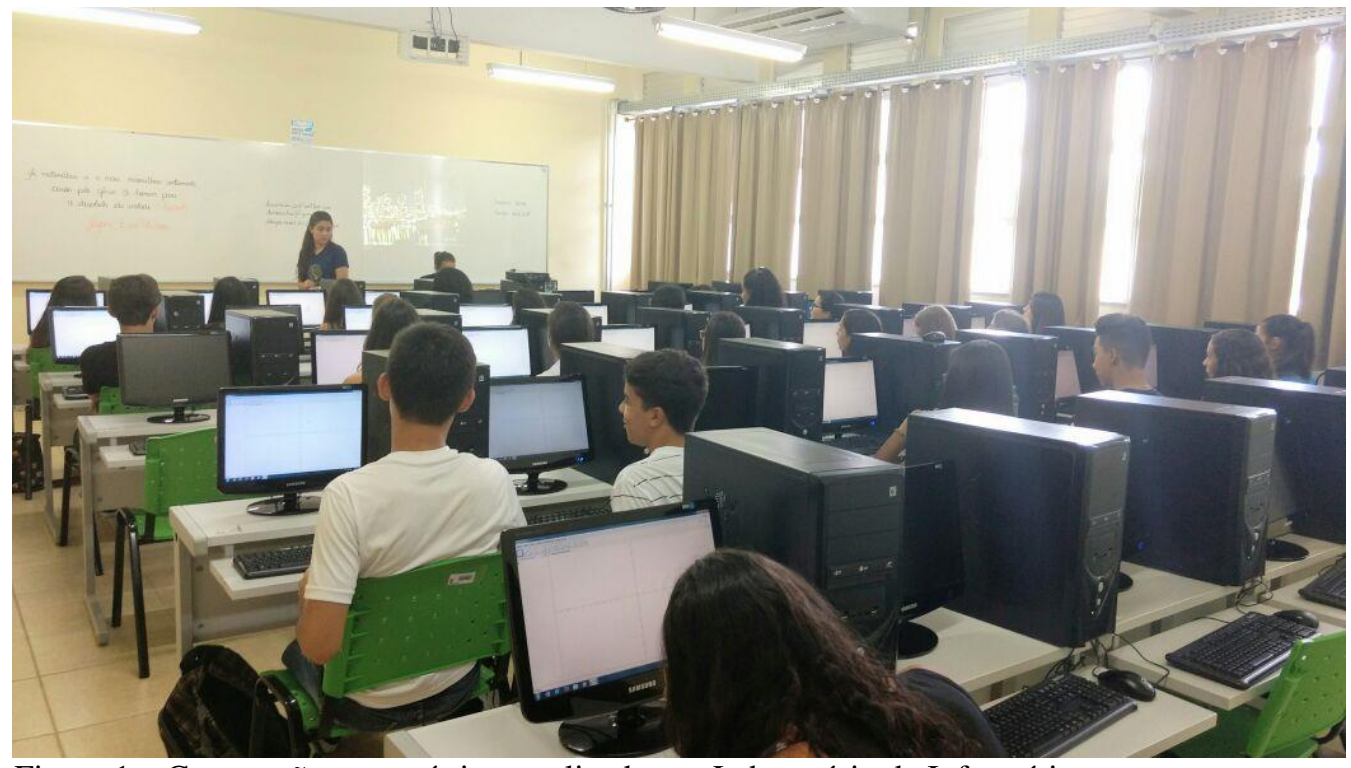

Figura 1 - Construções geométricas realizadas no Laboratório de Informática Fonte: Próprios autores.

Durante as atividades, os alunos propunham estratégias de resolver os problemas propostos, nesta etapa os conceitos aprendidos em geometria plana foram colocados e visualizados na prática. Através das manipulações e observações, foram feitas reformulações de maneira a ser validada a construção proposta. Os alunos desenvolveram as atividades através de discussões entre si e no momento em que alguma dúvida surgia, os conceitos de Geometria Plana eram relembrados, pelas ministrantes, como forma de concluir a atividade.

Posteriormente, foi realizado juntamente com os alunos, o passo a passo da construção de congruência e semelhança. Segue abaixo a atividade:

V. Siga o passo a passo e construa dois triângulos congruentes utilizando o caso lado ângulo lado (LAL)

Passo I: Antes de começar a construir habilite a malha e posicione os eixos de forma que vemos somente o primeiro quadrante;

Passo II: Construa um triângulo $\mathrm{ABC}$ com a opção Polígono da janela 5 da barra de ferramentas;

Passo III: Clique com o botão direito do mouse no interior do triângulo e selecione a opção Propriedades. Agora, escolha preenchimento "imagem" para o polígono P e clique em Aplicar; 
Passo IV: Marque o ângulo CBA e observe que na janela de álgebra aparecerá a medida do ângulo $\alpha$;

Passo V: Na janela 6 da barra de ferramentas escolha a opção Ângulo com amplitude fixa e clique em dois pontos distintos da tela. Quando a janela de ângulo de amplitude fixa se abrir, digite a medida do ângulo $\mathrm{ABC}=\alpha$ e em seguida clique em Aplicar. Logo após isso, aparecerá na sua tela o ângulo DED' que é congruente CBA. Observe na janela de Álgebra que o ângulo DED' foi chamado de $\beta$ e que ele tem a mesma medida do ângulo CBA;

Passo VI: Construa uma circunferência com centro em E e raio igual a "c", onde "c" representa a medida do segmento $\mathrm{AB}$;

Passo VII: De modo análogo, construa uma outra circunferência com centro em E e raio igual a "a", onde a representa a medida do segmento $\mathrm{BC}$;

Passo VIII: Trace a semirreta ED e a semirreta ED';

Passo IX: Determine o ponto, F, de interseção da ED com a circunferência de centro E e raio “a”. De modo análogo, determine o ponto, G, de interseção da ED' e a circunferência de centro em E e raio "c";

Passo $X$ : Construa agora o triângulo de vértice EFG, sem preenchimento, ou seja, preenchimento padrão e observe que esse triângulo possui $\mathrm{EF} \cong \mathrm{BC}, \mathrm{DED}^{\prime} \cong \mathrm{CBA}$ e $\mathrm{EG} \cong$ BA . Logo, os triângulos ABC e EFG são congruentes pelo caso LAL.

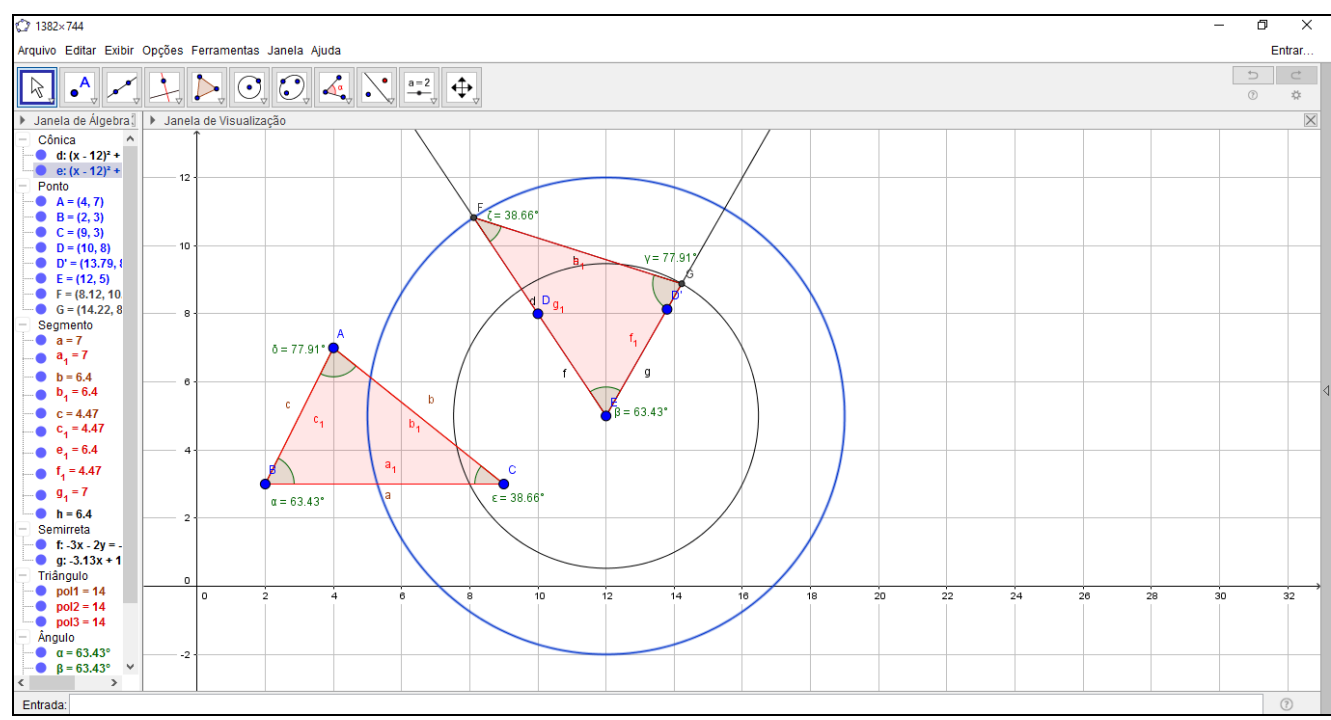

Figura 2 - Triângulos congruentes

Fonte: Próprios autores. 
VI. Siga o passo a passo e construa dois triângulos semelhantes ${ }^{7}$

Passo I: Habilite a malha do plano na Janela de Visualização, ou mesmo na janela com o botão direito do mouse, opção malha e posicione os eixos de tal forma em que vejamos o primeiro quadrante;

Passo II: Com a ferramenta Polígono, construa um triângulo qualquer ABC;

Passo III: Com a ferramenta Ponto, marque um ponto externo ao triangulo $\mathrm{ABC}$ e em seguida com a ferramenta Reta, trace retas que passe pelos vértices do triangulo $A B C$ e pelo ponto $\mathrm{D}$, criado anteriormente;

Passo IV: Usando uma ferramenta nova, Homotetia (janela 8), clique no interior do triângulo para selecioná-lo e, em seguida, no ponto D. Observe que a caixa de homotetia se abrirá pedindo o fator de ampliação ou redução. Digite, nesta caixa, o número 1.5 e mande aplicar. Um novo triângulo surgirá a partir do triângulo ABC e será chamado de A'B'C'.

Passo $V$ : Para verificar a razão de semelhança entre os dois triângulos $\mathrm{ABC}$ e A'B'C' que é igual a 1,5. Para isso, efetue a divisão das medidas dos lados do triângulo A'B'C' pelas medidas dos lados correspondentes do triângulo ABC. Por exemplo, usando a barra de entrada, digite b' / b, que representa o quociente da divisão das medidas dos lados $\mathrm{A}^{\prime} \mathrm{C}^{\prime}$ e AC. Depois obtenha os quocientes a'/ a e c'/c.

Passo VI: Usando a ferramenta Ângulo marque os ângulos dos triângulos, ABC e A'B'C', e observe que os ângulos correspondentes são congruentes.

\footnotetext{
${ }^{7}$ Adaptado de Bervian e França [s.d.].
} 


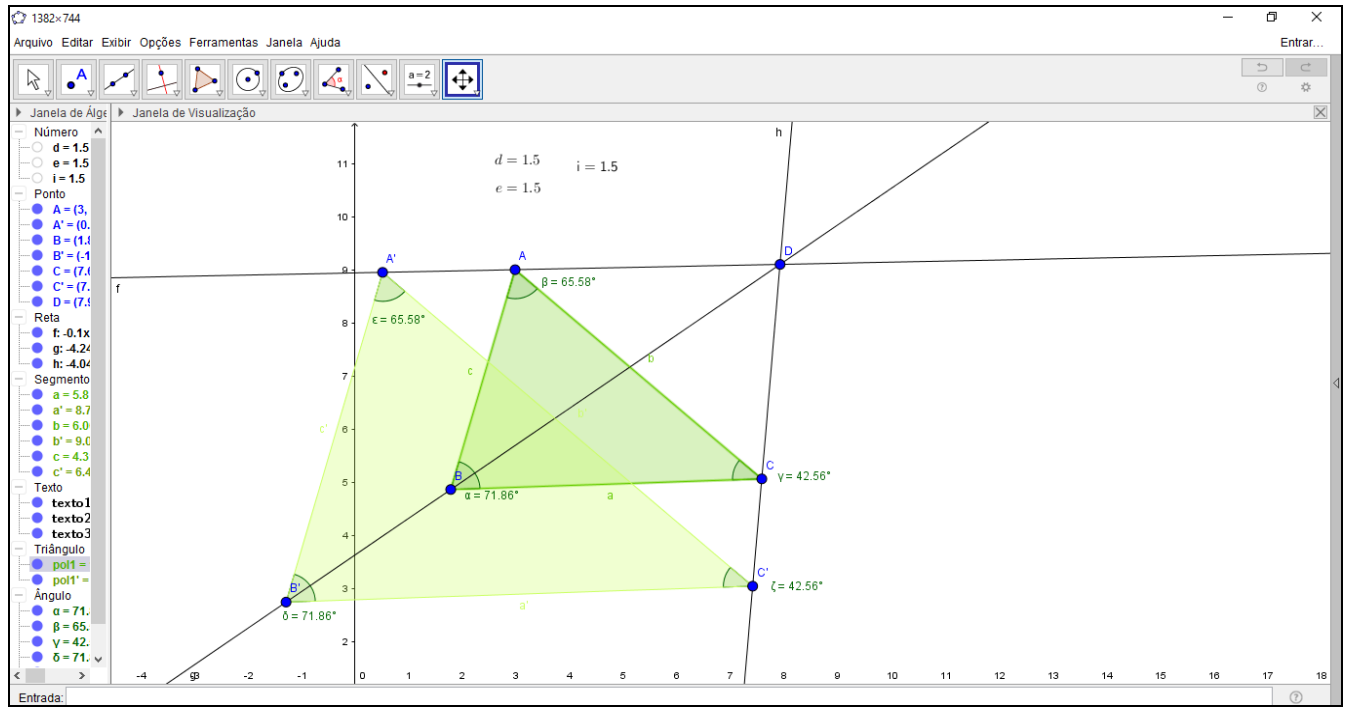

Figura 3 - Triângulos semelhantes

Fonte: Próprios autores.

Nas construções de semelhança e congruência de triângulos, os alunos puderam visualizar na prática os conteúdos teóricos que foram aprendidos em Geometria Plana.

Durante o minicurso, as construções dos triângulos escalenos, semelhantes e congruentes foram feitas juntamente com os alunos como forma de facilitar e reconhecer o manuseio do software Geogebra. As construções dos triângulos equilátero, retângulo e isósceles foram feitas pelos alunos e, na medida em que alguma dúvida surgia, as ministrantes relembravam os conceitos geométricos que foram explicados inicialmente para que as construções pudessem ser feitas.

Ao final, foi solicitado que os alunos respondessem um questionário de pesquisa, com o intuito de verificar os conhecimentos geométricos adquiridos e avaliar a atividade. Por fim, foi requisitada a construção de um mapa conceitual para verificação do conhecimento dos alunos. Nesta perspectiva, tem-se os mapas conceituais como uma abordagem mais prática, no sentido de diagramas que representam o conceito formado sobre determinado assunto.

Segundo Moreira (1997), mapas conceituais relacionam o conhecimento do aluno em estruturas hierárquicas de conexões significativas, onde cada ligação correta reflete o domínio do aluno pelo assunto. Seu cruzamento com as respostas do questionário, utilizadas na coleta de todo o material, permitiram uma melhor compreensão do estágio cognitivo de cada estudante.

Seguem abaixo, as questões do questionário de pesquisa:

1) Você tem domínio sobre o conteúdo de congruência e semelhança de triângulos visto no Ensino Fundamental? Justifique. 
Nascimento, Dandara Lorrayne do et al. Minicurso: construções de triângulos através do software Geogebra

2) Você tem domínio sobre o conteúdo de circunferências e ângulos formados por retas? Justifique.

3) Você já fez uso de algum software matemático em sala de aula? Qual?

4) Você já utilizou o software Geogebra? Onde?

5) Qual sua opinião sobre o uso do software Geogebra em sala de aula?

6) Você acha viável o uso de softwares matemáticos para melhor visualização geométrica? Justifique.

7) Qual sua opinião sobre a atividade desenvolvida?

8) Elabore um mapa conceitual sobre os conteúdos conhecidos de geometria plana.

\subsection{Resultados e discussões}

Pela Figura 4 pode ser observado o resultado das respostas obtidas no questionário de pesquisa:

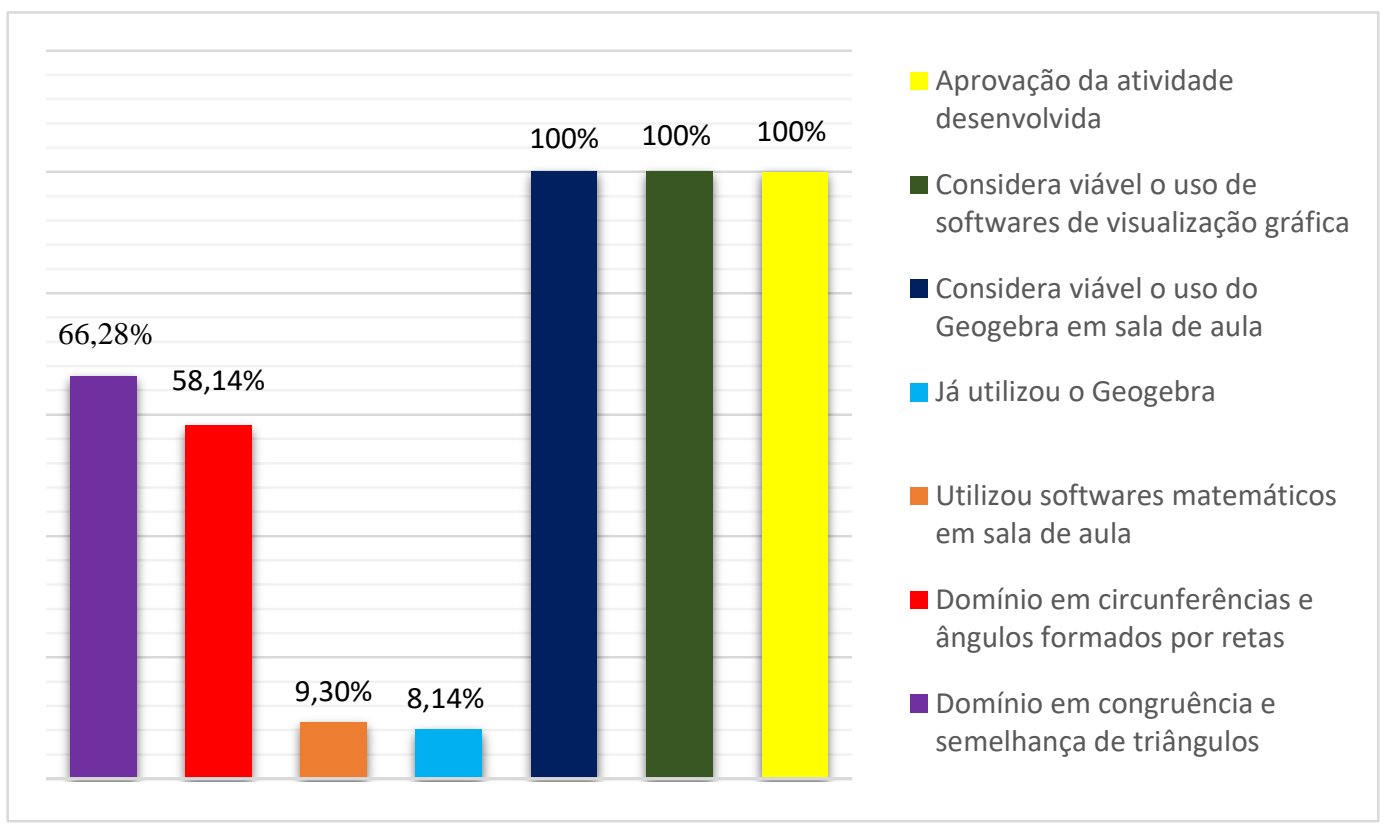

Figura 4 - Resultados do questionário Fonte: Próprios autores.

Analisando os resultados obtidos, pode-se observar que apenas 66,28\% dos alunos pesquisados declararam possuir domínio sobre o conteúdo de congruência e semelhança de triângulos e somente 58,14\% possuem domínio sobre o conteúdo de circunferências e ângulos formados por retas, analisando as respostas $65,12 \%$ dos alunos possuem domínio sobre os dois conteúdos simultaneamente. As principais justificativas dos alunos, por não possuírem domínio sobre esses conteúdos foram de que a professora que tiveram no ensino médio não gostava de passar conteúdos de geometria ou que não foram aprofundados e alguns alunos ainda disseram não terem visto esse conteúdo no ensino fundamental, mesmo sendo tópicos 
obrigatórios do Conteúdo Básico Comum (CBC) de Matemática do Ensino Fundamental ${ }^{8}$ (Eixo Temático III, tópicos 14, 15 e 18). Este fato, confirma as retratações utilizadas anteriormente, de que o ensino da geometria se encontra defasado devido a precariedade no processo de ensino aprendizagem vivenciada ao longo dos anos.

Observa-se também, que apenas 9,30\% dos alunos já utilizaram softwares matemáticos em sala de aula. Os softwares listados foram o Geogebra, SuperLogo, MathType e jogos de multiplicação. Em relação à utilização do Geogebra, somete 8,14\% dos alunos já utilizaram o Geogebra. Estes resultados indicam que mesmo a tecnologia estando presente cada vez mais no cotidiano das pessoas, ela ainda encontra dificuldades para ser utilizada em sala de aula a favor da aprendizagem.

Por fim, vale ressaltar que $100 \%$ dos alunos aprovaram o uso do software Geogebra em sala de aula e a viabilidade dos softwares matemáticos para melhor visualização geométrica, aprovando também a atividade desenvolvida. Dentre os principais comentários, foi destacado que o software ajudou na compreensão da atividade e na visualização, de maneira prática e divertida, auxiliando na consolidação dos conhecimentos prévios sobre o conteúdo trabalhado.

Ao analisar os resultados da primeira e segunda questão do questionário e compará-los com os mapas conceituais, algumas divergências foram evidenciadas. Nem todos os alunos que relataram possuir domínio sobre os conteúdos trabalhados apresentaram um mapa conceitual caracterizado de um conhecimento aprofundado, em contrapartida, alguns alunos que relataram não ter domínio, elaboraram mapas conceituais amplos e com conexões lógicas bem formuladas. Pela Figura 5 alguns resultados podem ser observados:

\footnotetext{
${ }^{8}$ MINAS GERAIS. Conteúdo Básico Comum (CBC). Proposta Curricular, 2006.
} 
Nascimento, Dandara Lorrayne do et al. Minicurso: construções de triângulos através do software Geogebra

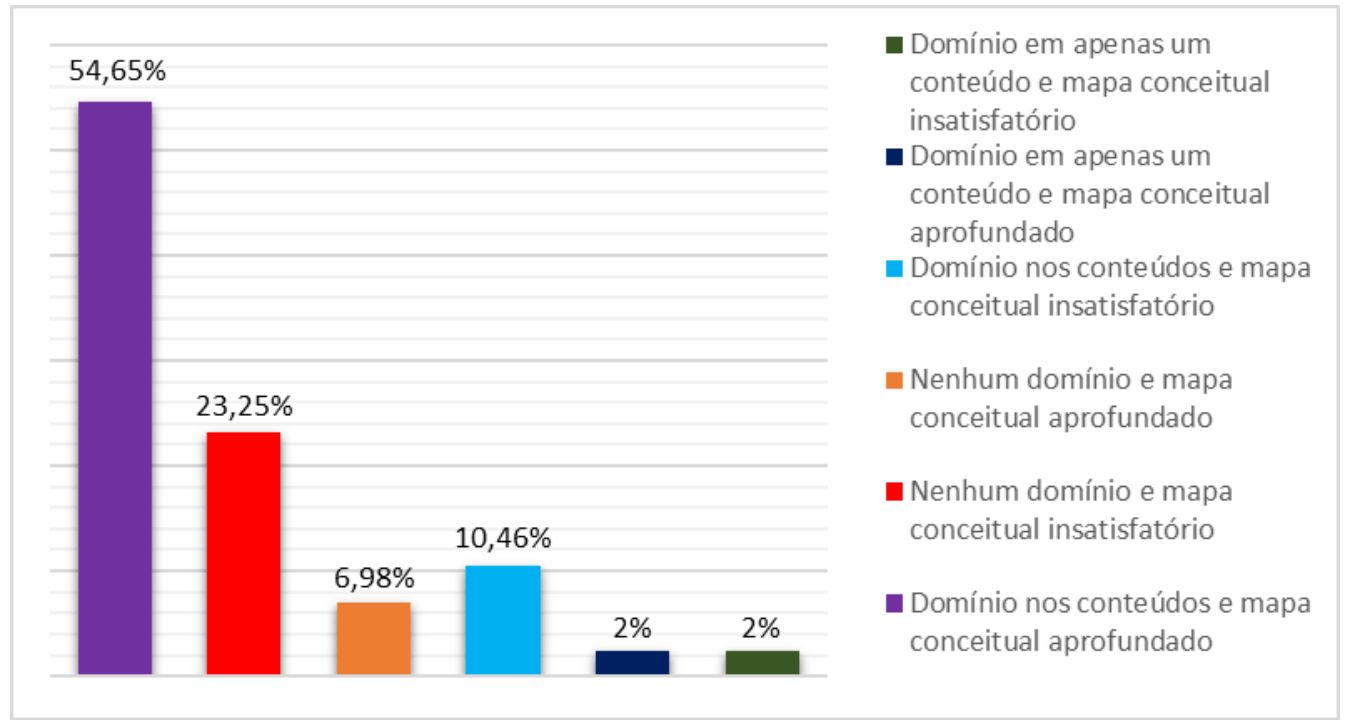

Figura 5 - Conteúdos e mapa conceitual

Fonte: Próprios autores.

Na Figura 5, pode-se observar que 54,65\% dos alunos possuem domínio sobre os dois conteúdos simultaneamente. Esses alunos elaboraram mapas conceituais com conexões lógicas aprofundadas, contrariando o resultado da primeira análise que relatou $65,12 \%$ dos alunos com domínios em ambos os conteúdos. Como retratado anteriormente por Moreira (1980), os mapas conceituais estabelecem as conexões lógicas significativas que o aluno possui acerca do domínio do conteúdo proposto, onde seu cruzamento com as respostas do questionário permitem uma melhor compreensão do estágio cognitivo do estudante. Considera-se, portanto, que este resultado $(54,65 \%)$ reflete verdadeiramente a quantidade de alunos que possuem domínio sobre os conteúdos trabalhados, sendo capazes de formular conexões lógicas aprofundadas de maneira satisfatória.

Observa-se também que $23,25 \%$ dos alunos não possuem domínios sobre os conteúdos propostos e, portanto, não foram capazes de elaborar mapas conceituais com conexões lógicas satisfatórias. Em contrapartida, 10,46\% dos alunos disseram possuir domínio nos conteúdos, contudo não apresentaram mapas conceituais satisfatórios. Este resultado retrata que existe certa dificuldade para alguns alunos em formularem o conhecimento em estruturas hierárquicas de conexões significativas.

Por fim, $2 \%$ dos alunos relataram ter domínio em um dos conteúdos e elaboram mapas conceituais insatisfatórios enquanto outros $2 \%$ elaboram mapas conceituais com conexões aprofundadas. Estes resultados sugerem quem nem sempre uma única forma de avaliação é suficiente para analisar se os objetivos do processo de ensino e aprendizagem foram 
alcançados, devendo sempre haver uma forma que possibilite o aluno descrever sua maneira de pensar e resolver o problema proposto.

\title{
3 CONCLUSÃO
}

Conclui-se que o ensino da geometria ainda sofre grande dificuldades, sejam elas pela falta de tempo, devido ao grande currículo de matemática a ser estudado ao longo do ano, ou também pela insegurança que o professor possui ao ensinar o conteúdo.

Neste sentido, os dados da pesquisa apresentados neste texto corroboram com o que as outras pesquisas apontaram, como Pavanello (1993) e Barbosa (2003), no que se refere à dificuldade no processo de ensino e aprendizagem da Geometria nos dias atuais.

O software Geogebra obteve a aprovação de todos os alunos pesquisados, sendo utilizado como auxílio para a formulação e compreensão dos conteúdos de geometria, através de manipulações, observações e discussões. De acordo com os resultados obtidos quanto à viabilidade do software na construção dos conceitos geométricos, pode-se afirmar que as ideias de Oliveira (2017, p. 5), Pereira (2012), entre outros autores citados, foram confirmadas nesta pesquisa.

Sugere-se uma maior aplicação deste recurso no ensino da geometria como forma facilitadora no processo de ensino e aprendizagem, propiciando e valorizando o real conhecimento do aluno.

\section{MINI-COURSE: BUILDING TRIANGLES THROUGH GEOGEBRA SOFTWARE}

\begin{abstract}
This work presents a methodological experience lived with students of the 1st year Integrated Technician of the Federal Institute of Education, Science and Technology of Minas Gerais Campus Formiga. A mini-course was taught with the purpose of introducing the use of Geogebra software allowing a new mathematical thinking through technological resources, through pedagogical application in the execution of some geometric constructions in the Computer Laboratory. It was decided to work exploratory-investigative activities, where students had the opportunity to test theoretical knowledge in practice through manipulations, observations and discussions. As expected, not all students had the prior knowledge that should be seen in elementary school, characterizing the main hypothesis that geometry teaching is still degraded, but with the use of technological resources the activities were satisfactory reaching the main objective in the teaching of flat geometry.
\end{abstract}


Keywords: Flat geometry. Constructions of triangles. Geogebra.

\section{REFERÊNCIAS}

BARBOSA, Paula Marcia. O estudo da Geometria. Instituto Benjamin Constant, 2003. Disponível em: <http://www.ibc.gov.br/images/conteudo/revistas/benjamin_constant/ 2003/edicao-25-agosto/Nossos_Meios_RBC_RevAgo2003_Artigo_3.pdf>. Acesso em: 23. jun. 2017.

BERVIAN, Rosely Ouais Pestana; FRANÇA, José Benício dos Anjos. GeoGebra: uma ótima ferramenta. [s.l.: s.d.]. Disponível em: <https://neiltonsatel.files.wordpress.com/2011/04/ geogebra_pequeno_manual_com_atividades.pdf>Acesso em: 01. out. 2016.

BORBA, Marcelo de Carvalho; PENTEADO, Miriam. G. Informática e Educação Matemática. 4. ed. Belo Horizonte: Autêntica, 2010.

BORBA, Marcelo de Carvalho; SILVA, Ricardo Scucuglia. R.; GADANIDIS, George. Fases das tecnologias digitais em Educação. Belo Horizonte: Autêntica, 2016.

BRASIL. Parâmetros curriculares nacionais: matemática. Secretaria de Educação Fundamental. Brasília: MEC/SEF, 1997. Disponível em: <http://portal.mec.gov.br/seb/ arquivos/pdf/livro03.pdf>. Acesso em: 02 dez. 2017.

LOVIS, Karla Aparecida; FRANCO, Valdeni Soliani. Reflexões sobre o uso do GeoGebra e o Ensino de Geometria Euclidiana. Informática na educação: teoria e prática, v. 16, n. 1, 2013. Disponível em: http://seer.ufrgs.br/InfEducTeoriaPratica/article/view/26104. Acesso em: 05 dez. 2017.

MOREIRA, Marco Antônio. Mapas conceituais e aprendizagem significativa. 1997. Disponível em: < https://www.if.ufrgs.br/ moreira/mapasport.pdf >. Acesso em: 20 dez. 2017.

OLIVEIRA, Dandara Lorrayne do Nascimento. Implicações do uso de tecnologias na prática docente no ensino da matemática. In: ENCONTRO DE EDUCAÇÃO MATEMÁTICA DE OURO PRETO, 6. 2017, Ouro Preto. Anais... Ouro Preto: Editora UFOP, 2017.

PAVANELLO, Regina Maria. O abandono do ensino da geometria no Brasil: causas e consequências. Zetetiké: Revista de Educação Matemática, v. 1, n. 1, p. 7-18, 1993. 
PELLI, Débora. As contribuições do software GeoGebra como um mediador do processo de aprendizagem da geometria plana na Educação a Distância (EAD) em um curso de Licenciatura em Pedagogia. 2014. Dissertação (Mestrado Profissional em Educação Matemática) - Departamento de Matemática, Universidade Federal de Ouro Preto, Ouro Preto. Disponível em: <http://www.repositorio.ufop.br/handle/123456789/4230>. Acesso em: 09 dez. 2017.

PEREIRA, Thales de Lélis Martins et al. O uso do software Geogebra em uma escola pública: interações entre alunos e professor em atividades e tarefas de geometria para o ensino fundamental e médio. 2012. Dissertação (Mestrado em Educação Matemática) Departamento de Ciências Exatas, Universidade Federal de Juiz de Fora, Juiz de Fora. Disponível em: <http://www.repositorio.ufop.br/handle/123456789/4230>. Acesso em: 09 dez. 2017.

PONTE, João Pedro da; BROCARDO, Joana; OLIVEIRA, Helia. Investigações matemáticas na sala de aula. 2. ed. Belo Horizonte: Autêntica, 2016.

SOUSA, Maria do Carmo de. A percepção de professores atuantes no ensino de matemática nas escolas estaduais da delegacia de ensino de Itu, do movimento matemática moderna e sua influência no currículo atual. 1999. Dissertação (Mestrado Profissional em Educação Matemática). Departamento de Educação, Universidade Estadual de Campinas, Campinas. Disponível em: <http://repositorio.unicamp.br/jspui/handle/ REPOSIP/251037>. Acesso em: 07 dez. 2017. 